\title{
Synthesis of Baconipyrone C
}

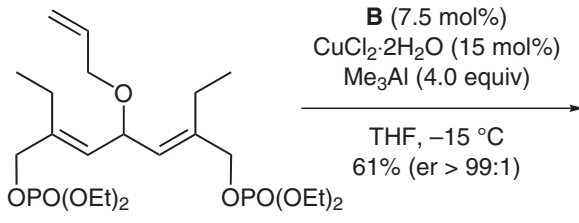

A<smiles>C=CCOC(CC)C(C)C(C)CC</smiles>

C
1. $\mathrm{Cp}_{2} \mathrm{ZrCl}_{2}$ (1.1 equiv) BuLi (2.2 equiv) THF,$-78^{\circ} \mathrm{C}$ 2. $\mathrm{O}_{3}, \mathrm{py}-\mathrm{CH}_{2} \mathrm{Cl}_{2}$
$-78{ }^{\circ} \mathrm{C}$, then $\mathrm{Ph}_{3} \mathrm{P}$ $80 \%$<smiles>CCC(=O)C(C)C(O)C(C)C(C)=O</smiles>

D

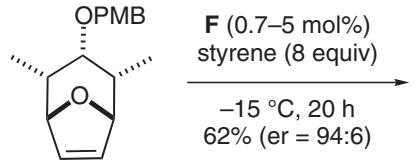

E<smiles>[R16]O[C@@H]1[C@H](C)[C@@H](C=C)O[C@H](/C=C/Cc2ccccc2)[C@H]1C</smiles>

G

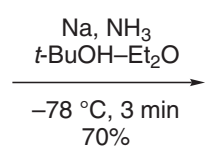

$70 \%$

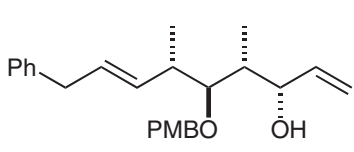

H

1. $\mathrm{CIMe}_{2} \mathrm{SiCH}_{2} \mathrm{CH}=\mathrm{CH}_{2}$, imidazole $\mid$ ring-closing 2. I (2 mol\%), $\mathrm{PhMe}, 40^{\circ} \mathrm{C}$ metathesis 3. $\mathrm{H}_{2} \mathrm{O}_{2}, \mathrm{KF}, \mathrm{KHCO}_{3}, \mathrm{THF}-\mathrm{MeOH} \downarrow 73 \%$

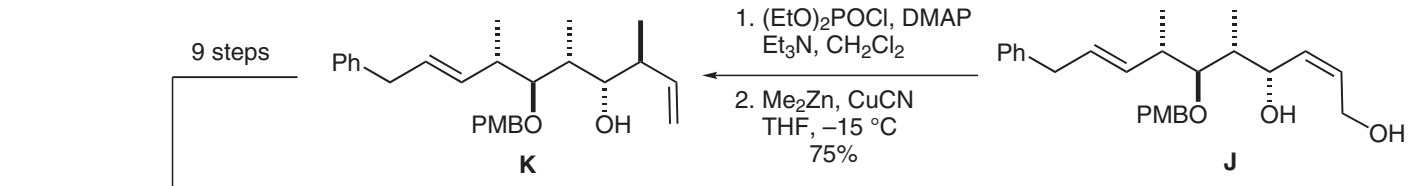

1. D (1 equiv)

1,3,5-trichlorobenzoyl chloride (30 equiv) DMAP (50 equiv), $\mathrm{Et}_{3} \mathrm{~N}$ (20 equiv)

$\mathrm{HO}_{2} \mathrm{C}$<smiles>CCc1oc(C(C)C(=O)[C@H](I)[C@H](OC(C)(C)C)C(C)C)cc(=O)c1C</smiles>
PhMe, r.t. $(68 \%)$

DDQ (2 equiv) pH 7 buffer, $\mathrm{CH}_{2} \mathrm{Cl}_{2}(90 \%)$<smiles>CCOC(=O)OCC</smiles>

(+)-Baconipyrone C
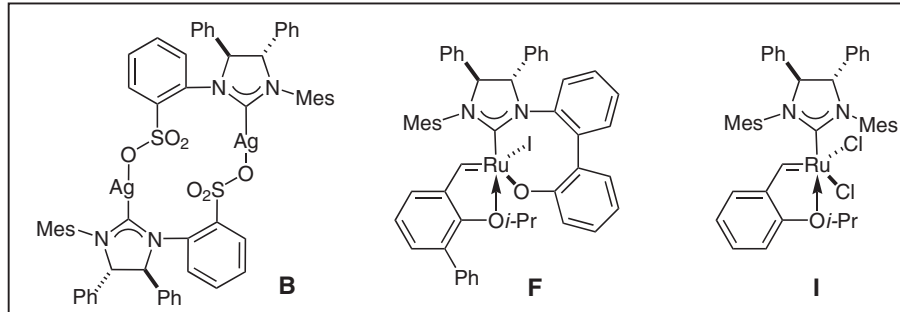

Significance: A new chiral Ru-based N-heterocyclic carbene complex $\mathbf{F}$ was deployed in the first asymmetric Ru-catalyzed asymmetric olefin metathesis reaction (E to $\mathbf{G}$ ). New $\mathrm{Ag}$ - and $\mathrm{Cu}$-based $\mathrm{N}$-heterocyclic carbene complexes were used in catalytic asymmetric allylic alkylation reactions (e.g. A to $\mathbf{C})$.

SYNFACTS Contributors: Philip Kocienski

Synfacts 2007, 9, 0895-0895 Published online: 23.08.2007 Dol: 10.1055/s-2007-968841; Reg-No.: K09207SF

\section{Key words}

allylic alkylation

asymmetric ringclosing metathesis

copper

ruthenium

N-heterocyclic carbenes

desymmetrization

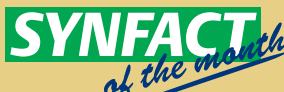

Comment: The high er obtained in the conversion of $\mathbf{A}$ to $\mathbf{C}$ demonstrates that allylic alkylation is under catalyst control whereas in the conversion of $\mathbf{J}$ to $\mathbf{K}$, substrate control governs the diastereoselectivity. 